
D:\Nsurg \Vol. 24, No. 3, Jul. - Sep., 2020\Nsurg-14.Doc
Fig. 1-2 Color
(A)
P. $248-252 \quad$ II

ORIGINAL ARTICLE

\title{
Intracranial CT Scan Findings in the Patients of Head Injury: An Early Experience at Dera Ghazi Khan Teaching Hospital
}

\author{
IQBAL AHMAD', MUHAMMAD HASSAN RAZA², AHMAD ABDULLAH' \\ SAMIA SAEED ${ }^{\mathbf{3}}$, SAIMA KHADIM ${ }^{1}$, SHAHIR BANO ${ }^{1}$ \\ Departments of ${ }^{1}$ Neurosurgery and ${ }^{3}$ Anatomy, D. G. Khan Medical College \& Hospital, D. G. Khan \\ ${ }^{2}$ Department of Neurosurgery, Lahore General Hospital (LGH), Lahore - Pakistan
}

Doi: 10.36552/pjns.v24i3.468

\begin{abstract}
Introduction: Head injury patients constitute a major number to any trauma emergency. Every head injury patient whose level of consciousness seems to alter, must be checked for brain injury. With the help of Computed Tomography (CT), Radiological evaluation has experienced a drastic change because it precisely explores the location and nature of lesion(s).

Material and Methods: This study included 408 patients that were admitted to the emergency of Teaching Hospital Dera Ghazi Khan, from October 2017 to September 2019. In this study, the location as well as nature of lesions were evaluated with the help of CT.

Results: CT results expressed that there was skull fracture (28.4\%), extra dural hematoma (20.6\%), diffuse intra cerebral hematoma (18.6\%), brain contusions (18\%), subdural hematoma (5.9\%), diffuse axonal injury (DAI) (4.4\%), subarachnoid hemorrhage (2.5\%) and pneumocranium (1.5\%). It was also noted that the males having age group between 20 - 35 years were mostly involved in head trauma and the reason for this was a road accident.
\end{abstract}

Conclusion: CT scan explained the location and nature of brain and skull lesions.

Keywords: Computed Tomography (CT), Road Accident, Head Trauma.

Abbreviations: DAI: Diffuse Axonal Injury. CT: Computed Tomography. MRI: Magnetic Resonance Imaging.

\section{INTRODUCTION}

Nowadays, Head Injury is considered as a main health problem that become cause of disability and death. In emerging countries, due to increase in road traffic, traumatic brain injury and accident rates also increased. Any type of Damage to Skull or Brain matter is included in Head injury. ${ }^{1}$ Head injuries are classified into two major types (i) Closed Injury (ii) Penetrating Injury to the brain. Closed injury is due to many factors such as road accidents, fall from height, hitting by vehicles while walking on road and assaults. Weapon bullet and several types of sharp objects are a major cause of penetrating head injury. In most of the cases, many other system injuries can also take place frequently along with traumatic brain injury which needs major attention prior treatment.

Brain Injury is considered as a common health problem all over the world, leading to disability and death in adults and children. Mortality and disability due to brain injury are increasing day by day. Death rate keeps on increasing due to motor vehicle or road traffic accidents. ${ }^{4}$ In today's neurosurgical practice, acute head injury has significant importance. Chances of mortality or disability in victims can be reduced by early diagnosis and treatment. Different types of diagnostic strategies are used by health professional in head injury cases.

Historically skull radiography was the widely used 
radiological procedure in head trauma cases, but presently cross sectional imaging, particularly CT has become the preferred choice ${ }^{2}$ especially in head injury management for a good number of reasons. ${ }^{10} \mathrm{CT}$ is faster in acquiring images, highly sensitive and accurate for detecting intracranial lesions requiring emergent neurosurgical decision (i.e., hemorrhages, hydrocephalus, contusion, and mass effect), and not contraindicated to metallic foreign bodies (e.g. gunshot fragment). Also been widely available and cheaper than Magnetic Resonance Imaging (MRI).

CT imaging is critical both in the diagnosis and management of head injury, particularly important is its role for triage in the acute setups in the determination of which patients require urgent neurosurgical attention. ${ }^{11}$ The aim of the study was to make a profile of head injury CT scans results and to outline the factors like age, gender to make early diagnosis and prompt treatment.

\section{MATERIAL AND METHODS}

\section{Study Design and Setting}

A retrospective study was carried out from October 2017 to September 2019.

\section{Inclusion Criteria}

408 patients with head injury, having findings on their CT scan of brain plain and bone window were included.

\section{Exclusion Criteria}

Those Patients were not enrolled in the study, which had polytrauma or those whose brain death was declared before doing a CT scan.

\section{Data Collection}

The data was collected on informed consents. Every patient underwent trauma related CT scan and all the relevant information including $\mathrm{CT}$ scan findings were transcribed to a pre-designed proforma to ensure uniformity.

\section{Clinical Management}

All patients were assessed according to Glasgow coma scale (GSS). The adverse effects of CT scan were disclosed to all the subjects before CT scanning. In this study, all CT scans with findings were included that were taken within 02 hours to 7 days after traumatic injury. CT scans showed primarily acute and sub-acute cases. A single CT scanner was used for this purpose having protocol as contiguous axial of $10-$ millimeters section base to vertex and 05 - millimeter section to posterior fossa.

Primary finding related to the clinical condition of patient was documented in case of more than one intracranial lesion. Treatment outcomes and method were not covered in this study.

\section{RESULTS}

\section{Gender Distribution}

In this study, male patients were 314 (77\%) and female patients were $94(23 \%)$. The gender ratio of male to female patients was $3: 1$.

\section{Age Range}

Age group ranging from 6 months to 74 years.

Average age for this data was 37.5 years. Most of the cases related to head injury were found in the age group of $16-35$ years $(39.5 \%)$ and after that $35-45$ years $(20 \%)$.

\section{Clinical Presentation}

Most of the cases of head injury were due to road accident $(47.8 \%)$, fall from height $(29.6 \%)$ assault $(19.9 \%)$ and sports injury $(2.0 \%)$.

Table 1: Mode of Head Injury.

\begin{tabular}{|l|c|c|}
\hline Mode of Injury & Number & Percentage \\
\hline RTA & 50 & 47.8 \\
\hline Fall & 30 & 29.3 \\
\hline Assault & 20 & 20.9 \\
\hline Sports Injury & & 2 \\
\hline
\end{tabular}

\section{CT Scan Findings}

Table 2 show different CT scan lesion(s) findings related to head injury.

Skull fracture had the highest value of $(28.4 \%)$, followed by extra dural hemorrhage (20.6\%). 18\% patients were with cerebral contusions or lacerations, only $(5.9 \%)$ were with sub dural hemorrhage, $4.4 \%$ were with diffuse axonal injury, followed by subarachnoid hemorrhage $(2.5 \%)$ and only (1.5\%) 
Table 2: CT Scan Lesions/Findings Related to Head Injury.

\begin{tabular}{|c|c|c|c|c|c|c|}
\hline \multicolumn{7}{|c|}{ Type of Injury } \\
\hline Skull Fracture & EDH & Contusions & SDH & DAI & $\begin{array}{c}\text { Sub-arachinoid } \\
\text { Hemmorriage }\end{array}$ & Pneumocranium \\
\hline 28.4 & 20.6 & 18 & 5.9 & 4.4 & 2.5 & 1.5 \\
\hline
\end{tabular}
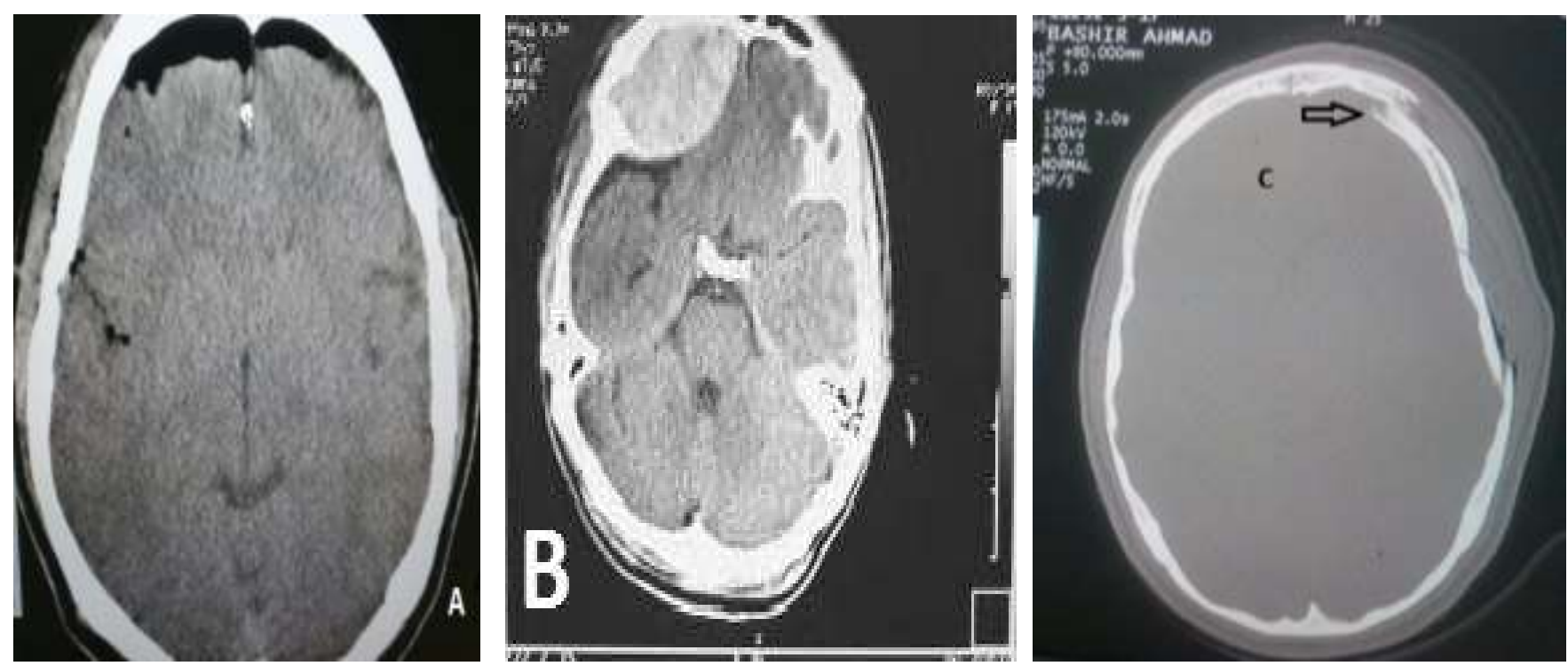

Fig. 1: CT Scan Brain Plain Showing Pneumocranium (A), Extra Dural Hematoma (B), Skull Fracture (C).

were with Pneumocranium.

When doing a CT scan for the patient with hemiplegia, extremities weakness and unconscious state findings were positive, while scans that were made regarding headaches, nausea and vomiting had less diagnostic worth.

\section{DISCUSSION}

Globally, the head injury is found commonly in young age people and particularly in males. In this study, the most common age groups were $2^{\text {nd }}$ and $3^{\text {rd }}$ decade of life span. These are most energetic groups that mostly spent their time out of the house due to the educational purposes or for their jobs and meet with accidents. It also observed that after 40 years of life there is a steady decline in road traffic accidents. While there is less likely involvement of patients with age group greater than 60 years because of their less mobility. These observations have been made similarly by other researchers. ${ }^{1}$

Male patients are more involved in head injury due to their active working routine as compared to females.
In our study there 3:1 male to female ratio of involvement in head injury. In most of the cases head injury is due to road accident and second main reason is falling from height. In the United States, most of the cases were related to head injury occurred due to road accident counting one-third in number. Studies in Egypt and Niger showed that most of the cases were related to head injury occurred due to road accident $t^{6,12,13}$ which is similar to our study in which most common mode of head injury was road accident included $47.8 \%$ patients and secondly falls included $27.3 \%$ patients.

Potential indications for performing $\mathrm{CT}$ in head injury setting include loss of consciousness, posttraumatic amnesia, persistent altered mental status, focal neurological deficit, signs of base of skull fracture. Various CT findings noted in our study were: skull fractures $(28.4 \%)$, extra dural hemorrhage $(20.6 \%)$ cerebral contusions (18\%), subdural hemorrhage (5.9\%), diffuse axonal Injury (4.4\%), subarachnoid Hemorrhage (2.5\%) \& Pneumocranium $(1.5 \%)$ which were similar to most of other studies. ${ }^{7-9}$

These abnormalities can progress to cause further 
neurological deteriorations and secondary injuries in the absence or delayed treatment. For instance, almost $50 \%$ of contusions have tendencies of enlarging over time, and of a potential occupying site for large intracranial hemorrhage formations. ${ }^{14}$ In this regard, the paramount expectation of the patient is recovery, which also is dependent on effective treatment based on accurate diagnosis. The neurosurgical or trauma team must need an efficient clinical guideline to guide imaging decision i.e., head trauma CT guideline to predict which head trauma patients can highly have traumatic brain injury and consequently would need CT scans performed. Thus, not all head trauma victims necessarily require $\mathrm{CT}$ scans. The $\mathrm{CT}$ guideline may help minimize the number of CT scans in trauma patient population, consequently controlling liberal access and over utilization, and indirectly reduce unnecessary patient irradiation and wastage of resources.

\section{RECOMMENDATION}

Motor traffic safety measures should be strictly enforced. Implementation of CT guideline to reduce unnecessary patient irradiation and wastage of resource. It is needed to establish appropriate Health care facilities including trauma centers in all the teaching hospitals of country with the accessibility of up-to-date machines of CT scan.

\section{CONCLUSION}

The study shows that CT findings in head injury were grossly skull fractures, extra dural hematomas, and contusions. Road side accidents and falls from height were generally the cause of all head trauma. Most commonly head trauma incidence was higher in males than females and in the most productive age persons than other age categories.

\section{REFERENCES}

1. Borczukp. Predictors of intracranial injury in patients with mild head trauma. Ann Emery Med. 1995; 25: 731-736.

2. Jorge Merino-De villas ante, Juan M, Taveras. Computerized tomography (CT) in acute head trauma. American Journal of Radiology. 1976; 146 (4): 765778.

3. Kelly C. Bordignon, Walter oleschko-Arruda. CT scan findings in mild head trauma a series of 2000 Patients Arg. Neuro-psiquiatr. 2002; 60 (2): 204-210.

4. GH Yattoo and Amin Tabish. The profile of head injuries and traumatic brain injury Deaths in Kashmir. Journal of Trauma Management and Outcomes. 2008; 2: 5 .

5. Asaleye CM, Famurewa OC, Komolafe EO et al. The pattern of computerized Topographic findings in moderate and severe head, injuries in ILE- IFE, Nigeria West African Journal of Radiology. 2005: 12.

6. Jennet B, Epidemiology of head injury. J Neurol Neurosurgery Psychiatry, 1996; 60: 363-369.

7. Macpherson BCM, Jennett B. CT evidence of intracranial contusion in relation to skull fracture. Clinical Radiology. 1990; 42: 321.

8. Seeling JM, Becker DP. Traumatic acute subdural haematoma. N Engl J Med. 1981; 304: 1511-8.

9. Takizawa T, Sato S. Traumatic subarachnoid haemorrhage. Neuro Med Chir. 1984; 24: 390-5.

10. Hydera AA, Wunderlich CA, Puvanachandraa P, et al. The impact of traumatic brain injuries: A global perspective. Neuro Rehabilitation. 2007; 22 (5): 341353.

11. Mutch CA, Talbott JF, Gean A. Imaging evaluation of acute traumatic brain injury. Neurosurg Clin N Am. 2016; 27: 409-439.

12. Onwuchekwa RC, Echem RC. An epidemiologic study of traumatic head injuries in emergency department of a tertiary health institution. J Med Trop. 2018; 20: 24-29.

13. Ogbeide E, Isara AE. Computed tomographic findings in elderly patients with head trauma in a Southern Nigerian tertiary hospital. IJMHDEV. 2014; 19: 32-49.

14. Lolli V, Pezzullo M, Delpierre I, et al. Emergency Radiology special feature: Review article MDCT imaging of traumatic brain injury. Br J Radiol. 2016; 89: 0849 .

\section{Additional Information}

Disclosures: Authors report no conflict of interest.

Ethical Review Board Approval: The study was conformed to the ethical review board requirements.

Human Subjects: Consent was obtained by all patients/participants in this study.

Conflicts of Interest:

In compliance with the ICMJE uniform disclosure form, all authors declare the following:

Financial Relationships: All authors have declared that they have no financial relationships at present or within the previous three years with any organizations that might have an interest in the submitted work.

Other Relationships: All authors have declared that there are no other relationships or activities that could appear to have influenced the submitted work. 
Address for Correspondence: Iqbal Khan Kharal

Department of Neurosurgery, D.G. Khan Medical College\& Hospital, Dera Ghazi Khan - Pakistan

\section{AUTHORS CONTRIBUTIONS}

\begin{tabular}{|l|l|l|}
\hline Sr.\# & Author's Full Name & Intellectual Contribution to Paper in Terms of: \\
\hline 1. & Iqbal Ahmad Kharal & Study design and methodology. \\
\hline 2. & Muhammad Hassan Raza & Paper writing, referencing, data calculations and \\
\hline 3. & Ahmad Abdullah & Data collection and calculations \\
\hline 4. & Samia Saeed & Analysis of data and interpretation of results etc. \\
\hline 5. & Saima Khadim & Literature review and manuscript writing \\
\hline 6. & Shahir Bano & Analysis of data and quality insurer \\
\hline
\end{tabular}

Date of Submission: 30-03-2020

Date of Revision: 03-9-2020

Date of Online Publishing: 25-09-2020

Date of Print: 30-09-2020 